Promoting high school boys' reading engagement and motivation: the role of the school psychologist in real world research

\title{
Cathy Atkinson
}

\author{
University of Manchester \\ Bury Educational Psychology Service
}

Ellen Wilkinson Building, University of Manchester, Oxford Road, Manchester, M13 9PL

Email: cathy.atkinson@manchester.ac.uk 


\begin{abstract}
It can be difficult for school psychologists to become involved in research within their day-to-day role. This paper details real world research undertaken in a single high school to identify and address mechanisms which were contributing to boys' literacy underachievement. In an attempt to promote reading engagement and motivation amongst high school boys, an affective reading intervention was delivered to Year 8 pupils in a single sex comprehensive school. The lack of desired outcomes prompted a systemic enquiry into boys' views and perceptions reading in this context. Reported here are findings from focus group interviews with staff and pupils which suggest that factors that facilitated or inhibited boys' reading were the result of complex interactions between socio-cultural influences, peer pressures, gender perceptions and literacy preferences. A motivational model is proposed as a useful framework for helping schools explore how schoolbased literacy practices might facilitate reading development.
\end{abstract}




\section{Introduction}

\section{School psychologists and real world research}

In identifying similarities in school psychology practice across 43 countries, Farrell et al (2007) noted international concerns that few school psychologists are actively engaged in research. Barriers cited included time, level of practitioner qualification and resources. Whilst acknowledging these issues, Rose and Garner (2006) propose that research might take place at a number of levels and advocate that researchers and practitioners collaborate in developing 'inquiry-based practice' to promote professional knowledge and help schools address current issues and challenges.

This study describes research undertaken in a single setting in which the author was working as a school psychologist. The rationale arose from discussions with school personnel about low levels of literacy attainment and how this might link to behavioural difficulties. This led the author to research issues relating to boys' literacy acquisition, develop an affective reading intervention and finally to investigate reasons for the lack of successful outcomes.

\section{Affective and motivational factors in reading}

Hastings and Henry (2006), describing the results of a survey conducted amongst 1,200 schoolchildren proclaimed that 'Reading is a closed book to today's children.' Amongst the 'uncomfortable revelations' were that reading was the preferred activity for only $15 \%$ of children and that many secondary pupils knew nothing about the classic texts on school reading lists.

To school psychologists, the findings will be somewhat less surprising. While widespread research has focused cognitive aspects of reading development, such as word recognition or phonological processing, the importance of affective factors has often been overlooked. Verhoeven and Snow (2001) argue that enthusiasm for reading is a prerequisite to learning to read and that 
reading motivation is as important as orthographic knowledge or comprehension strategies.

Another factor affecting reading engagement amongst high school pupils is the extent to which UK reading initiatives have predominantly addressed the needs of primary aged children (Atkinson, 2006). In the United States, the focus for policy development and public interest has also been early literacy instruction. Alvermann (2002) stresses the importance of keeping adolescents' interests and needs foremost in mind when planning a literacy curriculum for older children and of giving consideration to reading perceptions and levels of motivation. Explicit instruction on reading comprehension and study strategies and a wider range of reading resources are also encouraged (Moore et al, 1999).

Wigfield and Guthrie (1997) found that motivation predicted the amount and breadth of children's reading, positing that a variety of possible reading motivations could influence children's reading engagement and performance. These include intrinsic factors (such as curiosity and challenge), extrinsic influences (such as grades and recognition) and social motivators for reading (such as sharing meanings and compliance). Reeve (2001) hypothesised that an individual's motivation to approach or avoid a task is determined by the values attributed to it and the expectancy of success. Furthermore, Eccles et al $(1983 ; 2005)$ proposed that task value is an important factor in achievement motivation.

\section{Boys and reading}

The differential educational attainment of boys and girls has been widely noted for more than a decade, attracting attention both in the UK and internationally (Bright, 1998, Lee-Potter, 2003). Recently the Department for Education and Skills (DfES, 2007) noted that 'The gender gap arises mostly because of differences between boys and girls in language and literacy skills, reflected in differences in performance in English and other subjects which are literacy based. The gender gap is small or negligible for Maths or Science' (p. 5). However the strongest predictor of attainment is reportedly 
not gender but social class, with white boys accessing free school meals identified as a particularly vulnerable group (DfES, 2007).

There are numerous research findings, suggesting differential engagement in and motivation for reading for boys and girls (Barrs, 1993, 1998; Millard, 1997a, 1997b; Maynard, 2002). Barrs (1998) cites a host of factors affecting boys' literacy achievement including societal expectations; family influences; early experiences; peer group pressures and stereotyping; classroom contexts; parental expectations; behavioural issues and the range of literacy materials offered by schools. Millard (1997a) notes that while the predominant focus for reading in school is books, boys express less interest in the narrative genre. Furthermore boys and girls read for different purposes and these gender differences widen as they progress through school.

\section{Background to the study}

This research took place as part of a wider study into the relationship between literacy achievement and behaviour at a single sex boys' high school, situated within an area of high social disadvantage in a large urban conurbation in the North of England. Although there is some degree of ethnic diversity, the majority of pupils would fit the description of 'white working class boys' over whom concerns about achievement have often focused (Woodward, 2000; DfES, 2007). Limitations of the study in relation to its generalisabilty to other educational contexts are acknowledged.

Initially, the author worked with mixed ability registration groups of Year 8 boys (aged 12-13) on an affective reading intervention which comprised a series of activities over five sessions aimed at promoting reading engagement and motivation. However, quantitative and qualitative feedback suggested that the intervention was not achieving the desired outcomes. Furthermore, there appeared to be some negative consequences of the intervention, such as pupils expressing disenfranchisement with the sessions; actively non- 
participating pupils attracting negative teacher attention; and participating pupils being barracked by peers.

From an ethical perspective the intervention was therefore terminated and reasons explored for why it was unsuccessful. These included logistical factors (e.g. pupils arriving late), researcher factors (that the researcher was unfamiliar to most of the boys) and the suitability of the materials. One particularly interesting factor, evident from session transcripts and pupil observations was the extent to which the socio-cultural context of the classrooms appeared to influence pupil engagement. For example some pupils were derided for answers given during the whole class discussion. This did not appear to relate to the content of their suggestions, but to the fact that they were responding to the task. Additionally two boys in one of the registration groups appeared to exert a powerful social influence over other members of the group. Pupils within the class appeared to be conscious of the views of these boys when responding to the activities.

\section{Outline of the study}

To try and establish reasons for the lack of desired outcomes and define a more effective way of considering affective factors in reading, further research was proposed. This sought to gather further information about the views and perceptions held about school-based literacy practices, by literacy support staff and by the Year 8 boys. In order to identify practices that were facilitative of promoting reading engagement and motivation, it aimed to address the following questions:

- What are the reading preferences of the boys in this particular context?

- How do socio-cultural factors, within school and within the broader educational context, impact on boys' reading engagement and motivation?

- How do school-based literacy practices facilitate or inhibit boys' reading engagement and motivation? 
While the focus for this paper has been boys' literacy, there is no suggestion that literacy practices for adolescent girls should not attract the same levels of attention. Indeed, many of the issues raised in this research are equally pertinent to girls.

\section{Procedure}

A helpful standpoint from which to consider the complexities of systemic work is that of illuminative evaluation, as outlined by Burden (1998). This offers a post-positivist or interpretive approach where the emphasis is upon 'interpreting educational practices, participants' experiences, institutional procedures and management problems in ways that are recognizable and useful to those for whom the study is made' (Parlett and Dearden, 1977, cited by Burden, 1998, page 16).

With this paradigm in mind, a research approach was sought which aimed to gather qualitative information about pupils' reading experiences from the point of view of different stakeholders. This paper reports on one aspect of the data gathering, which involved hosting focus groups with staff and students. Additional information was also gathered from school policy information, individual interviews and questionnaire feedback, but the reporting of these additional data is beyond the scope of this paper.

\section{Participants}

Two focus group interviews took place with literacy teachers and support staff in the school in question (Groups S1 and S2). The groups comprised seven and five members respectively. The staff taking part in the focus groups all spent some of their time working within the school's learning support department and had some responsibility for working with pupils with the most severe and persistent literacy difficulties who were accessing 'Wave 3' support, the highest level defined in the UK National Literacy Strategy (DfES, 2003a). 
A further focus group interview was also held with eight boys attending a Reading Challenge Group (Group R1) who were accessing the less intensive Wave 2 support (DfES, 2003a)). The focus of the Reading Challenge Group was to promote enjoyment of and engagement in reading, rather than to improve technical reading skills.

Finally, two pupil focus groups were made up of boys of mixed ability who had previously been recipients of the affective reading interventions delivered to registration groups (Groups P1 and P2). Each focus group was comprised of six boys selected by their form tutor, three of whom who were positive about reading and three who could be described as 'reluctant readers'. No distinction was made between these groups of pupils and no information was received about the boys before or after the session. Participation in the discussion groups was entirely voluntary and therefore, although the boys had differing attitudes to reading, those who were very negative about reading are less likely to have volunteered (or been asked) and may have been underrepresented.

A summary of the focus group interviews conducted is shown in Table 1 below:

Table 1: Summary of focus group interviews

\begin{tabular}{|c|l|}
\hline Interview Group & \multicolumn{1}{|c|}{ Description } \\
\hline S1, S2 & Literacy Support Staff \\
\hline R1 & Pupils accessing additional literacy Wave 2 support \\
\hline P1, P2 & Mixed ability pupils \\
\hline
\end{tabular}

Prompt questions were presented to staff and pupil focus group attendees prior to the discussion, to stimulate thinking and discussion. These included:

- What helps young people to enjoy literacy/reading in school?

- Is there anything that prevents young people reading at school?

- How can young people support each other with their reading? 
- What would help young people enjoy reading more?

During each meeting, key points from the discussion were noted down. A précis of the main themes emerging was then provided to attendees at the end of the session, to ensure consensus that the most important points had been summarised. Additionally the sessions were audio taped and transcribed and data from the transcriptions were then used to enrich these agreed themes.

\section{Outcomes from discussions with staff and pupils}

Key themes emerging from focus group interviews with staff in groups S1 and S2 are shown in Box 1 below:

\section{Box 1 Key themes emerging from Staff Focus Groups}

- Resources offered in school often do not reflect the interests or sociocultural context of the boys staff were working with;

- Reading practices observed within the boys' home and community contexts (e.g. by adult role models) may not promote reading engagement and motivation;

- Socio-cultural factors are likely to be influential in facilitating or inhibiting reading opportunities and determining boys' reading choices;

- Creating 'supportive' environments might be helpful in enabling boys to participate in supported, shared reading experiences;

- It may be helpful to develop resources that promote a broader understanding of reading behaviours and their impact on adult life. 
Ideas emerging from the Reading Challenge Group (R1) are summarised in Box 2 below. They were subsequently presented to the mixed ability groups (P1 and P2) for further discussion and consideration.

\section{Box 2: Key themes identified by the pupil groups}

- Young people like to read a wide range of things. Some of the most popular choices are non-fiction books such as the Guinness Book of Records or books that tell you how to do things, as well as magazines, newspapers and fiction books.

- Young people are very good at identifying all the different ways they can read, things they can read and different reasons for reading. They are also good at thinking about different reasons for reading after leaving school.

- The things young people read at school and out of school can sometimes be quite different.

- Young people like to make their own choices about reading. Some young people would like to read more and others feel they are fine as they are.

- Having lots of interesting things to read in school might be a good way of encouraging young people to read more.

- If young people are going to talk about reading, it might be better to do this with adults they know, rather than in a group where different people have different views. 
The findings will now be explored in more depth with reference to the key questions.

\section{What are the reading preferences of boys in this particular context?}

The boys in groups $\mathrm{P} 1$ and $\mathrm{P} 2$ identified that providing a wide range of resources in school was a useful way of promoting reading. These include local newspapers; magazines (about sport, cars, pop stars, films, Superbowl and Batman); comics; playstation games; swap cards; and computers, as well as a range of fiction and non-fiction books. They noted that teachers selected most reading material covered in school and that greater pupil involvement in reading choices would be preferable.

When discussing book preferences, the boys were able to identify a range of popular genres which included books covering the following areas of interest: cars; war; history; ghosts; horror; football; guns and fighting. Both groups were positive about reading non-fiction materials and some of the boys mentioned that they would seek out this type of text to read in the "book boxes' that were available to them in some lessons. One boy remarked that, "...there's too much fiction" in schools, while another specifically cited a preference for non-fiction books:

"I like reading war books to find out about the war and like history books and that... and the Guinness Book of Records'. I don't really like fiction books because they're a bit too far-fetched. They get a bit tedious and boring."

The boys also felt that they would like greater input into the range of books available in school.

How do socio-cultural factors, within school and within the broader educational context, impact on boys' reading engagement and motivation?

\footnotetext{
${ }^{1}$ The Guinness Book of records, published by Guinness World Records Limited is a compendium of world records, detailing both human achievements and extremes in the natural world.
} 
The boys in groups $\mathrm{P} 1$ and $\mathrm{P} 2$ noted that peers could exert both positive and negative influences over reading behaviour, for example:

"When in class you're reading or you get something wrong, the person next to you normally helps you out."

and;

"If they said, like, what are you going to do tonight and you said, "Oh l'm going to sit in and read a book," they'd go... they'd slag you."

Staff supporting boys with reading difficulties (groups S1 and S2) expressed stronger views suggesting that boys were not supportive of each others' reading such as:

"They get laughed at."

"I was in French this morning and Mark was doing really well... and they all dived on him and called him a "geek" and the teacher said, "I'm sick of them picking on him because he does his work" and they all start on him. I'm literally standing there protecting him. I said, "Leave him alone."”

Staff noted that boys received unsavoury comments from peers when they did engage well with their reading. As well as being called a "geek", the term "gay" was also used pejoratively to refer to pupils who engaged in reading, and more generally in learning. One member of staff commented:

"It's one of the things that's always struck me about this school. We've got such a wide racial mix and l've never really come across any racism, as such, but the biggest insult is "you're gay". That's the insult 
"you're gay", "you're a geek". The biggest insult is that you would be gay to enjoy reading."

The boys also identified that outside school, other activities conflicted with opportunities to engage in home-based reading. Some authors (Coleman and Hendry, 1999; Moore et al, 1999) have commented that competing social pressures may be one reason for the decline in reading engagement amongst adolescents. Some boys did, however, associate certain behaviours, such as reading the newspaper, reading about music and reading last thing at night to go to sleep, as pleasurable and relaxing experiences.

Pupils within Group R1 (those accessing Wave 2 provision) initially stated that they did not read at home. However, during the course of the discussion, it became clear that their terms of reference were different for home and school. Pupils did not immediately identify themselves as readers within their home contexts because the items they reported reading out of school (newspapers, magazines, the TV guide, 'cheats' for playstation games and text messages) differed from what they were reading in school (predominantly books).

Contradictory to the views expressed by literacy support staff in groups $\mathrm{S} 1$ and S2, that reading practices observed within the boys' home and community contexts (e.g. by adult role models) may not promote reading engagement and motivation (see Box 1 ) the boys in groups P1 and P2 boys gave positive comments about how people at home modelled reading behaviour or provided support.

Reasons for this difference are unclear. It is important to note that pupils in groups $\mathrm{P} 1$ and $\mathrm{P} 2$ were reporting direct instances of parental reading, whereas the staff were offering perceptions based on their involvement with the boys and their parents/carers. Additionally, discussions with staff suggested that parents/carers with literacy difficulties (who therefore might engage less in reading) appeared to be over-represented amongst pupils receiving specialist support. 
Another boy suggested that adult role models influence the reading habits of young people.

"I think that teenagers read the things that their mums and dads read. They look at their mum and dad reading and they think, "Um, my mum's reading that", and when she's finished they'll read it."

Although not directly questioned about the differences in reading behaviour of boys and girls, both groups offered suggestions which indicated they had gendered perceptions of reading, such as:

"More boys like guns or fighting. Girls tend to like make up and horses."

"We prefer magazines with sports and things like that. Cars, newspapers and that."

The boys subsequently identified other books that they considered to be appropriate for girls and not for boys. One boy cited his cousin as typifying girls' reading habits because she read a lot of books. Barrs (1993) found that boys would not consider reading books that dealt with the feminine experience and rejected books because of their content, title and even the picture on the cover.

\section{How do school-based literacy practices facilitate or inhibit boys' reading engagement and motivation?}

The literacy support staff in groups S1 and S2 were critical of the literacy curriculum, complaining that it consisted predominantly of books and did not tend to reflect the reading preferences of boys outside school, which included magazines, newspapers and cards.

When asked to what extent materials offered within the literacy curriculum reflected the socio-cultural backgrounds of the pupils, one member of staff 
voiced strong opinions about the relevance of the National Curriculum to the lives of the pupils attending the school.

"No [the curriculum] doesn't reflect... and the thing is, you're only allowed so many books on the National Curriculum and unfortunately the National Curriculum is set by people who can read and read a lot, and probably like classic books. But they don't live in an inner city area as a kid with limited literacy skills, so... well that's the way the education system works isn't it. Certain people make the rules for people in a completely different set of circumstances. That's the problem I think."

Furthermore, staff felt that an important development would be to consult with staff in more diverse areas about how to engage young people from a wider range of backgrounds.

"...what might be nice, once in a while, is while they were setting the National Curriculum, to come to see the English Co-ordinators and ask them what they think should be on there. Because what they tend to do is... "These books would be good to read", etcetera and then for the socially deprived, we'll stick 'Kes'² or something on there as a token gesture. They don't actually ask what they think might engage them and help them achieve and get involved in reading."

The boys in groups $\mathrm{P} 1$ and P2 offered a greater range of views about curriculum delivery, indicating positive features as comparing books with the film versions, whole class discussions and taking roles in book reading. Contrary opinions were that some people did not enjoy reading aloud and that sometimes they were made to read books that they did not like.

\footnotetext{
2 'Kes' is a reference to the novel 'A Kestrel for a Knave', by Barry Hines (1969) which tells the story of a young boy growing up amongst economic disadvantage, a turbulent home life and troubled schooling and of the solace he finds in his relationship with a kestrel named 'Kes.'
} 
The boys reported limited use of the school library for reading and borrowing books, although they claimed to use the computer and Internet resources regularly. They noted that they would prefer a greater range of materials to be available, such as comics, as well as what they described as "hard books".

\section{Discussion}

This research evolved from an evaluation of an affective literacy intervention into an exploration of the factors that influenced boys' reading engagement and motivation within a particular school context. What emerges is a formative, not summative, piece of research that prompts further questions about how school-based practices influence boys' reading engagement and motivation. A range of factors was reported to facilitate and inhibit reading engagement including socio-cultural influences, peer responses, gender perceptions and literacy preferences.

The scope and breadth of the key themes emerging from the focus groups with staff and pupils were wide ranging. However, for the purposes of this paper, the implications of the study for the school psychologist will be discussed under the following four headings:

- Reading preferences

- Reading and the curriculum

- Reading at home and at school

- Social cultural influences

\section{Reading preferences}

The desire amongst pupils to access more stimulating reading resources was perhaps the most important factor emerging from discussions with pupils and staff and echoes a call for a wider range of reading materials to be made available to adolescents (Moore et al, 1999; Alvermann, 2002).

This argument can be broken down into two strands. The first concerns the need for resources that are interesting and accessible. The focus for 
secondary school literacy practices continues to be the narrative (Millard, 1997a; Hall and Coles, 2001) and reading initiatives focused on the promotion of fiction books, albeit boy friendly ones (DfES, 2003b, Kent County Council, 2004; SLA, 2007). However, findings from this study support research which highlights a preference amongst many boys for non-fiction materials (Barrs 1993; Millard 1997a; Hall and Coles, 1999).

Secondly it is important to consider the range of reading resources available in school and to what extent they represent contemporary reading practices for adolescent boys. Hall and Coles (2001) propose that school systems may be failing to capitalise on the fact that outside school popular literacies might be serving boys very well (e.g. the technological change in information supply). However, there is now increasing acknowledgement that girls and boys have different learning preferences and that boys' interest in topics influences their level of understanding, motivation and engagement (Oakhill and Petrides, 2007).

Worthy et al (1999), concerned about the gap between student reading preferences and materials that schools provide and recommend, posited that: ...perhaps the answer to motivating students to read is as simple as encouraging them to follow their interests (page 24).

\section{Reading and the curriculum}

Alloway and Gilbert (1997) note that often the impetus is on reforming the child rather than the system, whereas pedagogical practices within schools can be influential in determining academic progress for different groups of pupils. Factors cited for boys' literacy underachievement by the Council for the Curriculum, Examinations and Assessment (CCEA) in Northern Ireland (CCEA, 2004) are predominantly to do with boy characteristics (e.g. attitudes, genetic influences, puberty) rather than school-based literacy practices. More significantly, reasons given in response to the Frequently Asked Questions (FAQ) on the DCSF Gender and Achievement website (DCSF, 2008) for boys' underachievement in schools make no reference to the potential contribution of school-based literacy practices. 


\section{Reading at home and at school}

Although the importance of home school literacy links is well documented (Wolfendale and Topping, 1996; International Reading Association, 2002) often these tend to be defined in school terms (Hall and Coles, 2001). One way of engaging and motivating readers may be for schools to offer greater acknowledgement of less formal literacy practices accessed in everyday life. In this research, some of the boys did not immediately identify themselves as readers within their home contexts, because the items they reported reading out of school are often unrecognised by official school curricula. Hall and Coles (2001) suggest that home reading experiences tend to be discounted by schools and pupils alike.

Millard (1997b) summarises research findings suggesting that boys' home literacy preferences (e.g. computer and hobby magazines; comic strip books) were discouraged or not allowed during lesson time. Hall and Coles (2001) note that outside school, many boys are able to demonstrate motivation and competence in reading and suggest that school literacy practices should complement and enhance home and community literacy practices.

\section{Socio-cultural influences}

Socio-cultural factors and peer interactions appeared to have a significant impact on the boys' responses and also contributed to the lack of success of an affective reading intervention. Discussions with staff and pupils suggested that they also influence pupil participation in and feelings about school-based literacy practices.

The need to consider socio-cultural issues in boys' achievement is defined by Younger et al (2005) who noted that some boys go to considerable lengths to protect their macho images and sense of self worth and that one mechanism for doing this is disruptive or non-conformist behaviour. This can have the additional effect of protecting boys from possible failure but their behaviour often makes them 'key players' in affecting the engagement of the group. 
However, in order to challenge such a culture, the mechanisms which contribute to it must be understood. This research suggests that perceptions exist about what constitutes appropriate masculinities and that these are 'policed' within this particular school. Sometimes this was through use of what might be termed '... abuse that is used to discriminate against pupils on the grounds of ability or attitude to work, e.g. 'swot', 'bof' or 'geek" (DfES, 2003b, page 33), at other times, through the use of the term 'gay.'

From extensive interviews with high schools Duncan (1999) concluded that 'gay' had duality of meaning for boys. As well as being recognised as meaning homosexual, 'the ascription of 'gay' replaced qualities which other boys had, such as sporting prowess, being a good fighter, cheeking teachers and hanging around with cool mates doing cool activities such as smoking and swearing' (page 19). Martino (1999) observes how homophobic comments can be used to police masculinities and can be directed towards boys who demonstrate behaviours that are inconsistent with dominant views of masculinity.

Further exploration of the factors that contribute to the policing by peers of masculinities in school might be useful for school psychologists working at a systemic level. This could be explicitly addressed through the development of school policies, anti bullying initiatives and Personal Health and Social Education (PHSE) programmes.

\section{Using a motivational framework to promote reading engagement and motivation}

One theoretical framework which is cognisant of these different factors and the interaction between them is the Expectancy-value theory (EVT). It posits that achievement behaviours are determined by expectancies of success and incentive values. An individual's values for particular goals and tasks can help explain why a child chooses one activity over another (Jacobs and Eccles, 2000). Furthermore, an individual's choice, persistence and 
performance can be explained by their beliefs about how well they will do on the activity and the extent to which it is valued (Wigfield and Eccles, 2000).

As this research illustrates, there is a significant number of cultural, social and affective factors that contribute to a child's choice of achievement tasks, as well as their persistence and performance. Wigfield and Eccles (2000) propose an expectancy-value model of achievement motivation which is shown in Figure 1. 
Figure 1 Expectancy-value model of achievement motivation, (Wigfield and Eccles, 2000)

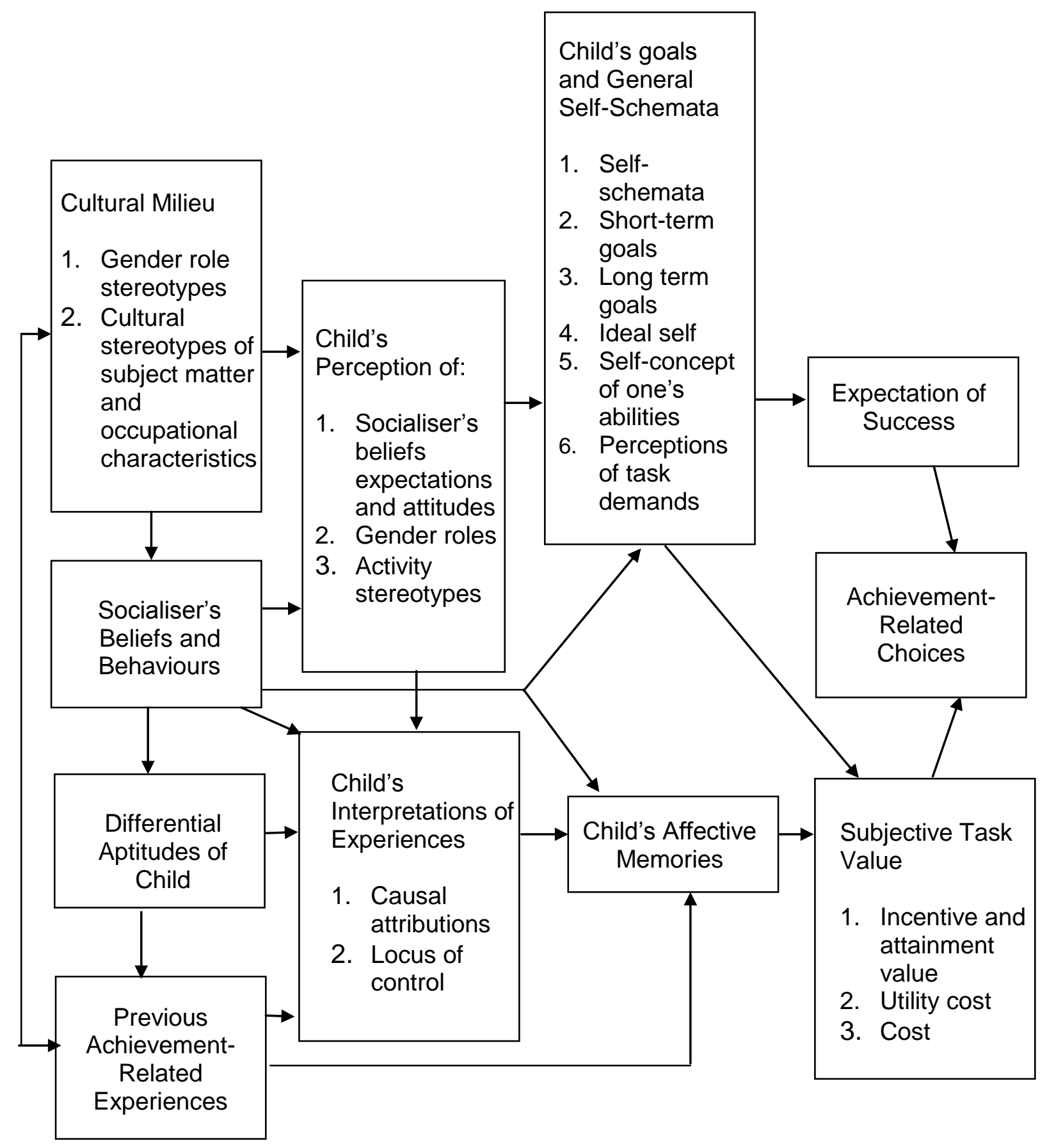

Although complex, this model provides a useful framework for understanding the broader influences that might impact on an individual's motivation. It suggests that in order to begin to understand the mechanisms that affect 
boys' reading engagement and motivation, a deeper understanding of their child's socio-cultural context needs to be established. Perhaps a simplified version of the framework could facilitate discussions about how schools can examine their own learning practices, at an individual, group and whole school level.

Motivation represents an important psychological construct. However, it is extremely difficult to identify all the determinants of behaviour and how these interact with learning and achievement. This may be one reason why teaching and learning discussions in school may not always consider motivational factors. School psychologists can support schools in developing an awareness of these factors and how these can facilitate or inhibit reading engagement.

\section{Broader implications for school-based literacy practice and the role of the school psychologist}

Hutchinson (2004) offers a possible role with regard to the question of raising boys' attainment, suggesting that school psychologists should 'engage intelligently and critically in this debate and others' (page 13). It is important that school psychologists are not just seen to be working with children at the margins (Thomson, 1996; MacKay, 2002) but are involved in helping schools to understand the contextual complexities of learning and applying psychological thinking to promote the learning of all children.

Recognition of the factors that can impact on boys' literacy underachievement, such as societal and parental expectations, constructions of masculinity and peer group pressures, can help to inform practice within schools, as well as interventions for individual pupils. It is important for school psychologists to contribute to thinking about a literacy curriculum that reflects the specialist needs of boys and other groups vulnerable to literacy underachievement. 
Finally, this study illustrates how an illuminative evaluation research paradigm can be used to develop an understanding of the mechanisms that can impact on motivation (and subsequently literacy learning) within a particular context. This model of thinking positions the school psychologist as a real world researcher and promotes the type of collaborative, inquiry based practice advocated by Rose and Garner (2006).

For school psychologists reliant on predominantly positivist approaches to research, this can present something of a paradigm shift. Indeed, Burden (1998) notes that '...even now experienced practitioners with good honours degrees in psychology often express surprise that alternative approaches to research could be possible, let alone should be possible' (page 15). However, illuminative evaluation can offer a consultative, flexible and responsive research approach. Furthermore, it may be a more feasible methodology to accommodate within day-to-day practice and one which is useful to practitioners; both in terms of generating knowledge and understanding about a specific context and in promoting the development of strategies and systems to address identified issues.

\section{$\underline{\text { References }}$}

Alloway, N. and Gilbert, P. (1997) 'Boys and Literacy: Lessons from Australia', Gender and Education 9(1): 49-58.

Alvermann, D. E. (2002) 'Effective Literacy Instruction for Adolescents', Journal of Literacy Research 34(2): 189-208.

Atkinson, C. (2006) 'Key Stage 3 pupils' views about reading'. Educational Psychology in Practice 22(4): 321-337.

Barrs, M. (1993) 'Introduction: Reading the Difference', in M. Barrs and S. Pidgeon (eds.) Reading the Difference, pp.1-11. London: Centre for Language in Primary Education. 
Barrs, M. (1998) 'Texts and Subtexts: Literacy, Gender and Achievement', in M. Barrs and S. Pidgeon (eds.) Boys and Reading. London: Centre for Language in Primary Education.

Bright, M. (1998) 'Girls really are better than boys: official'. Observer, 4 January.

Burden, B. (1998) 'Illuminative Evaluation'. Educational and Child Psychology 15(3): 15-24.

Coleman, J. C. and Hendry, L. (1999) The Nature of Adolescence. London: Routledge.

Council for the Curriculum, Examinations and Assessment (CCEA) (2004) School Improvement: Focus on Boys. Guidance on Improving Attainment, Particularly in Literacy. Belfast: CCEA.

Department for Children, Schools and Families (DCSF) (2008) The Standards Site: Gender and Achievement.

www.standards.dfes.gov.uk/genderandachievement. Accessed 14.03.08.

Department for Education and Skills (DfES) (2003a) National Literacy Strategy: Targeting support: choosing and implementing interventions for children with significant literacy difficulties. London: DfES.

Department for Education and Skills (DfES) (2003b) Using the National Healthy Schools Standard to Raise Boys' Achievement. London: DfES.

Department for Education and Skills (DfES) (2007). Gender and Achievement: The Evidence on Pupils in England. London: DfES.

Duncan, N. (1999) Sexual Bullying: Gender conflict and pupil culture in secondary schools. London: Routledge. 
Eccles, J. S., Adler, T. F., Futterman, R., Goff, S. B., Kaczala, C. M., Meece, J. and Midgeley, C. (1983) 'Expectancies, values and academic behaviours'. In J. T. Spence (ed.) Achievement and achievement motives, pp.78-146. San Francisco: Freeman.

Eccles, J. S., O'Neill, S. A. and Wigfield, A. (2005) 'Ability Self-Perceptions and Subjective Task Values in Adolescents and Children'. In K. A Moore and L. Lippman (eds.) What do children need to flourish? Conceptualizing and measuring indicators of positive development pp. 237-249. New York: Springer.

Farrell, P., Jimerson, S. R. and Oakland, T. D. (2007) School Psychology Internationally: A Synthesis of Findings, in Jimerson, S. R., Oakland, T. D. and Farrell, P. (eds) The Handbook of International School Psychology pp 501-509. Thousand Oaks: Sage.

Hall, C. and Coles, M. (2001) 'Boys, books and breaking boundaries: developing literacy in and out of school'. In W. Martino and B. Meyenn (eds) What about the boys? Issues of masculinity in schools pp. 211-221. Buckingham: Open University.

Hastings, C. and Henry, J. (2006). 'Reading is a closed book to today's children'. Telegraph, 23 July.

Hutchinson, D. (2004) 'A Critical Evaluation of "Raising Boys' Attainment"' Educational Psychology in Practice 20(1): 3 - 15.

International Reading Association (2002) Family-School Partnerships: Essential Elements of Literacy Instruction in the United States: A Position Statement of the International Reading Association. Newark: International Reading Association. 
Jacobs, J. E. and Eccles, J. S. (2000) 'Parents, Task Values and Real-Life Achievement-Related Choices' in C. Sansone and J. M. Harackiewicz (eds.) Intrinsic and Extrinsic Motivation: The Search for Optimal Motivation and Performance pp. 408-433. Orlando: Harcourt.

Kent County Council (2004) Boys can do better. Kent: County Print and Design.

Lee-Potter, E. (2003) 'Rescue plan for the weaker sex', Secondary Education, 3 April.

MacKay, T. (2002) 'Discussion Paper-The Future of Educational Psychology', Educational Psychology in Practice 18(30): 245-254.

Martino, W. (1999) 'Cool boys', 'Party Animals', 'Squids' and 'Poofters': interrogating the dynamics and politics of adolescent masculinities in school'. British Journal of Sociology in Education 20(2): 239-255.

Maynard, T. (2002) Boys and Literacy: Exploring the Issues. London: RoutledgeFalmer.

Millard, E. (1997a) Differently Literate: Boys, Girls and the Schooling of Literacy. London: Falmer Press.

Millard, E. (1997b) 'Differently Literate: gender identity and the construction of the developing reader'. Gender and Education 9(1): 31-48.

Moore, D. W., Bean, T. W., Birdyshaw, D. and Rycik, J. A. (1999). 'Adolescent Literacy: A position statement'. Journal of Adolescent and Adult Literacy 43(1): 97-112.

Oakhill, J. and Petrides, A. (2007). 'Sex Differences in the Effects of Interest on Boys' and Girls' Reading Comprehension'. British Journal of Psychology, 98: 223-235. 
Parlett, M. and Dearden, G. (eds.) (1977) Introduction to Illuminative Evaluation: Studies in Higher Education. London: Wiley.

Reeve, J. (2001) Understanding Motivation and Emotion. Orlando: Harcourt College Publishers.

Rose, R. and Garner, P. (2006) 'Enquire within: taking possession of the research of teaching and learning'. Support for Learning, 21(1): 2-3.

School Library Association (SLA) (2007). Riveting Reads plus Boys into Books. Swindon: SLA.

Thomson, L. (1996) 'Searching for a Niche. Future Directions for Educational Psychologists'. Educational Psychology in Practice 12 (2): 99-106.

Verhoeven, L. and Snow, C. E. (2001) Reading Engagement in Individuals and Groups. Mahwah, N.J: Lawrence Erlbaum Associates, Inc.

Wigfield, A. and Eccles, J. S. (2000) 'Expectancy-Value Theory of Achievement Motivation'. Contemporary Educational Psychology 25: 68-81.

Wigfield, A. and Guthrie, T. (1997) 'Relations of Children's Motivation for Reading to the Amount and Breadth of Their Reading'. Journal of Educational Psychology 89 (3): 420-432.

Wolfendale, S. and Topping, K. (eds.) (1996) Family involvement in literacy: effective partnerships in education. London: Cassell.

Woodward, W. (2000) 'Single sex lessons plan to counter laddish culture'. Guardian, August 21.

Worthy, J., Moorman, M. and Turner, M. (1999) 'What Johnny likes to read is hard to find in school'. Reading Research Quarterly 34(1): 12-27. 
Younger, $\mathrm{M}$ and Warrington, $\mathrm{M}$ with Gray, J., Rudduck, J., McLellan, R., Bearne, E., Kershner, R. and Bricheno, P. (2005). Raising Boys' Achievement. London: DfES. 